null • Vol. 2, No. 8

\title{
Review: .break .dance
}

\author{
Brittnay L. Proctor ${ }^{1}$
}

${ }^{1}$ University of California, Irvine

Published on: Aug 16, 2021

DOI: $10.21428 / 3 e 88 f 64 f . c 62 a 7450$

License: Creative Commons Attribution 4.0 International License (CC-BY 4.0). 


\section{Project}

.break .dance

\section{Project Director}

Marisa Parham, University of Maryland-College Park

\section{Project URL}

http://archipelagosjournal.org/issue03/parham/parham.html\#choreo

\section{Project Reviewer}

Brittnay_L. Proctor, University of California, Irvine

\section{Project Overview}

\section{Marisa Parham}

Form is content in .break .dance, and that form is intentionally errant, to use Edouard Glissant's term for intentional acts of wandering that are retrospectively revelatory of the self and its relations. It began with an image, the nodding figure in black, standing in front of a plantation manor in Beyoncé's video for "Formation." Her nods move over and under the beat, recalling to me Zora Neale Hurston's writings about asymmetry in Black Atlantic expressive traditions. Which in turn moved me to Antonio Benítez-Rojo's theory of the Caribbean machine. Which in turn moved me to thinking about nuances between polyrhythmic sound, asynchrony, and glitch aesthetics. Which then moved me to Ralph Ellison and Kwame Dawes-to what Kwame Dawes describes as "stop time," a kind of syncopation (in the break, in the cut, break it down) that can "seduce us and enliven us with the illusion and reality of how rhythm can be manipulated"-animation. This in turn moved me to a larger theory of animation-the sense of sound and movement that arises out of the negative spaces between things, which returns .break .dance to the multiple kinds of violence animated in Beyoncé's Lemonade texts, and that .break .dance finally brings together as a meditation on the distance between sound and image in Hiro Murai's video for Flying Lotus and Kendrick Lamar's “Never Catch Me," and the use of sound and movement to collapse time and space in Jonathan Demme's rendition of Baby Sugg's ringshout in the film version of Toni Morrison's Beloved. And many other things.

.break .dance is an interactive creative non-fiction longform choreo-essay of about fifteen thousand words, but because it is comprised of a variety of layered, time-based, 
and branching experiences, an average reader's experience comes in a bit closer to five thousand words. It also has a companion piece, an exploratory longform digital essay titled "Breaking, Dancing, Making in the Machine: Notes on .break .dance." If .break .dance centers the orchestration of voice, sound, and affect-various kinds of ghostly animations-then "Breaking, Dancing, Making" more resolutely connects that work to the overall project's concerns with matters of algebraic remix, digital computation, and experiential recursion, as historically expressed in African-American and Black Caribbean intellectual thought. Both projects take their major cues from Black American music, Caribbean philosophy and poetry, and numerous techniques of electronic literature, what I describe elsewhere as the potential of Black digital humanities to show rather than tell, which draws genealogical connection to traditions of Black Atlantic expressive texts that, as Zora Neale Hurston anthropological work teaches us, theorize themselves.

Writing about .break .dance in this way highlights its conceptual underpinnings, but it is important to note that it is made to be engaged by a wide variety of audiences. Because it is built out of its own gaps, audiences are invited to enter it on their own terms. Ntozake Shange uses the term choreopoem to describe her 1976 dramatic masterpiece, For Colored Girls Who Have Considered Suicide/When the Rainbow Is Enuf. A choreopoem, and by extension a "choreo-essay," is a text that moves quickly and constantly across expressive modalities-form and genre-in order to amplify the deep dimensionality of Black Atlantic experience. The idea is simply that different aspects of any individual person's experience might best be expressed in forms different from other aspects. At the same time, the invocation of a form or genre also brings with it all the social meanings of that form-the part of the self that is also a compendium of other selves, the parts of self-expression that draw exponentialized power though recitation and remix. As I describe in the .break .dance section "stars in my pocket," it is in "mining gaps, intersubjective spaces between intuition and groove, [that] it becomes more clear how the things we carry with us can also be honed into powerful acts of decryption, into strategies for joy and resistance, the dance against the break."

Play is centered in .break .dance, as "play" describes the combination of intentional and intuitive processes that produce critical thought out of citational practice, the incitation or invitation into the improvisational. For some users, .break .dance might help them experience new ways to connect theories of "the digital" to histories of Black American and Black Caribbean expressive and philosophical traditions. But because it is also just essentially a critical mix tape, other users might simply 
experience it as an engaging playlist for meditating on bits of popular music and image in new and exciting ways.

Indeed, this sense that .break .dance plays and is meant to be played with is deeply embedded in the project's form. There are sections, for instance, where the user is invited to move paragraphs into their own essay page, or others from which readers can submit their own paragraphs, which are ported directly into the project.

Discursively it operates as "a series of interlocking machines moving toward a state of flux," again in reference to Benítez-Rojo. There are pages in .break .dance and "Breaking, Dancing, Making" that some readers might never find (because they would not think to look) while other users might assume such pages exist because they arrive to the project with a sense of where some of the arguments might be heading, a sense of responding to cultural signaling that I discuss elsewhere, for instance in "Sample _. Signal| Strobe." Further, because readers will fall upon varying paths and Easter eggs - hidden gems of reference-throughout the project, .break .dance, like a mixtape, invites the user into a personal relationship with the text. What the reader receives as "the text" is also a thing that the reader has in fact made through their own reading thereof, even as .break .dance is in fact the expression of an argument about Black Atlantic life.

In terms of programming, .break .dance was produced in HTML 5 and P5.js, in order to give it maximum flexibility while also giving the project a reasonable shot at being archivable in the future. I say more about its programming in "instructions" and "about," which are part of the prefatory material of .break .dance, and where I describe this programming choice as one of the project's many technical expressions of Black Atlantic digital humanities. Both .break .dance and "Breaking, Dancing, Making" have also been distilled into an interactive Tumblr bibliography, which doubles as a social media site for the projects. The citation site is accessible through each page's title click, and was built collaboratively with Sheila Chukwulozie who, along with Lauren Tuiskula, helped me track the project's numerous literary, sound, and visual citations. Currently under redevelopment, the citation site is being updated to include more citations for the two projects' visual and programming cues, in order to emphasize the importance of inspiration, and also as a reminder of the multiple digital traditions out of which the projects emerge.

\section{Project Review}

\section{Brittnay L. Proctor}


Published in archipelagos (Issue 3, Slavery in the Machine, July 2019), Marisa Parham's .break .dance is a meditation on "the idea of being haunted by internet experience." 1 It uses the paradigm of "critical hauntology" to 1 ) consider the affective ether of digital experience and 2) visualize and sound "Black diasporic existence [as] a digitizing experience."르 Emerging between Parham's previous Black digital humanities work, "Sample | Signal | Strobe: Haunting, Social Media, and Black Digitality," and her new work Black Haunts in the Anthropocene, a book-length interactive project that focuses on memory, haunting, digitality, and Black environmental experience, .break .dance is polyphonic. It harmonizes the voices and performances of thinkers across genre/gender, including Sylvia Wynter, C.L.R. James, Christina Olivares, Keguro Macharia, Mikael Owunna, Beyoncé's Lemonade (i.e. Melina Matsouka's video for the single "Formation"), Hiro Murai's video for Flying Lotus, and Kendrick Lamar's song "Never Catch Me."

The project builds upon Fred Moten's theorizing in and around "the break," arguing that digitizing embodies the machinations of the break: ...glitching...movement... interruption...polyrhythm... ephemerality...what users might experience as the active pursuit of interruption or the search for the intermediary spaces within black digital experience. By digitizing "the break," the project is continuously unfurling new paths and instantaneous moments of rupture. Parham achieves these breaks by using digital tools like HTML, JavaScript, and CSS. As such, .break .dance defamiliarizes users of web technologies with which they are most familiar. This is no small feat. The phenomenology of digital experience is oft-theorized as white, linear, and disembodied. .break .dance, through the movement of text, GIFs, and images, reorients linear temporality typical to the phenomenological purchase of white digital reading and browsing. The project also masterfully showcases the importance of speculative scholarship for reimagining methods used in humanistic inquiry.

The utilization of tendwa symbols of Congolese cosmology to navigate the project parallels the use of HTML to disrupt linear experiences of the digital, insisting that the telos of black diasporic digital experience is rupture, nonlinearity, and passage. Circumventing the longing for idealized community or a homeland for black people living in diaspora to return to, Parham's .break .dance's ingenious use of digital methods offers different modes of theorizing black relationality across space, sound, and time. Users may navigate the project wondering if (black) sound is an immersive facet of the project or a metaphor for the temporal dimensionality that Parham is concerned with. 
Nonetheless, .break .dance leaves us with further considerations, chief of them being how black diasporic digital experiences offer new entry points into conceptualizing sound and blackness. The emerging field of black feminist sound studies should turn to Parham's project(s) to further consider its relationship to data visualization. For example, how might black feminist sound studies use works like Marisa Parham's .break .dance as the inspiration to visualize black sound via digital humanities methods. Overall, the project deftly animates the haptics of "blackness, space, and time...glitches-errors that reveal structures, and breaks" that emerge from black being in an antiblack world.

\section{Footnotes}

1. Marisa Parham, "Breaking, Dancing, Making in the Machine: Notes on .break.dance," archipelagos, Issue 3, "Slavery in the Machine," July 2019.

2. Marisa Parham, "Sample | Signal | Strobe: Haunting, Social Media, and Black Digitality" In Debates in the Digital Humanities 2019, edited by Matthew K. Gold and Lauren F. Klein (Minneapolis; London: University of Minnesota Press, 2019), 104. 